\title{
Self-authorship and creative industries workers' career decision-making
}

Dawn Bennett and Sophie Hennekam

\begin{abstract}
Career decision-making is arguably at its most complex within professions where work is precarious and career calling is strong. This article reports from a study that examined the career decisionmaking of creative industries workers, for whom career decisions can impact psychological wellbeing and identity just as much as they impact individuals' work and career. The respondents were 693 creative industries workers who used a largely open-ended survey to create in-depth reflections on formative moments and career decision making. Analysis involved the theoretical model of selfauthorship, which provides a way of understanding how people employ their sense of self to make meaning of their experiences. The self-authorship process emerged as a complex, non-linear and consistent feature of career decision-making. Theoretical contributions include a non-linear view of self-authorship that exposes the authorship of visible and covert multiple selves prompted by both pro-active and reactive identity work.
\end{abstract}

\section{Keywords}

Arts careers, career aspirations, precarious work, career development, gender, arts, artists 
The creative industries are commonly defined as those "supplying goods and services that we broadly associate with cultural, artistic, or simply entertainment value" (Caves, 2000: 1). Workers in most of these creative industries experience a "continually unfolding, self-managed patchwork of concurrent and overlapping employment arrangements" (Bennett and Bridgstock, 2015: 264). Moreover, portfolios of work often include roles outside the creative industries (Cunningham and Higgs, 2010). Dominated by contingent and highly competitive work (Eikhof, 2014), creative work tends to be obtained through networks and personal reputation (Smith and McKinley, 2009), with each creative project seeking to maximize the skills of different combinations of people (Daskalaki, 2010). As such, network membership is crucial to the process of securing and maintaining work (Thanki and Jeffreys, 2007), particularly in the early career phase (Luonila and Johansson, 2016). These networks, however, can also be exclusionary and difficult to access (see Smith and McKinlay, 2009; Wreyford, 2015).

The study reported here involved male and female creative workers, but we were mindful of empirical evidence that gendered work prevails within the creative industries (Banks and Milestone, 2011). Gendered work is defined, organized, divided and valued in a way that reflects the (unequal) relation between men and women, and creative industries workers whose practice encompasses multiple work settings can move in and out of gendered settings on a regular basis. This includes within organizations, where Acker (2007: 5) has observed organizational gendering described as “pervasive patterns of difference [and] a basic principle of social organization”.

An additional concern was the under-representation of women in many creative industries, including applied fields such as architecture, web design, advertising and creative media (Skillset, 2010). In the United Kingdom, for example, only $16 \%$ of the women in these industries are aged 50 or above compared with $25 \%$ of men, suggesting that men are more likely to persevere in these careers. Shade and Jacobson (2015) also assert that women tend to earn less than men and are more likely to undertake unpaid work. In line with this, Windels and Lee (2012) observe that paternalism 
and masculine cultures can lead female creative workers to doubt their abilities and that they are more likely to have their abilities questioned by others. Hennekam and Bennett (2017) add that women may also encounter normalized sexual harassment practices.

The extent to which these trends prevail within or across creative industries is not known, but researchers acknowledge that women in male-dominant organizations report less job satisfaction (McKeen and Burke, 1994), higher intentions to quit (Burke and McKeen, 1996) and increased anxiety and stress (Evans and Steptoe, 2002; Yoder, 2002). Particular considerations within the creative industries include irregular hours of work (Eikhof and Warhurst, 2013; Gill, 2002), frequent travel (Randle et al., 2007) and unequal power relations (Hesmondhalgh and Baker, 2009).

Entry into the creative industries is rarely predicated on the expectation of high salaries or stable work; rather, it draws people with a passion or calling for their creative practice (Coffey, 2012). The contingent and protean nature of creative work suggests that complex identity work will inform career decision-making throughout the career lifespan, and this study employed Baxter Magolda's theory of self-authorship (1999) to view this career decision-making process.

The complexity of work within many creative industries is beyond that which can be captured by large-scale data collections, thus both quantitative and qualitative studies are needed (United Nations, 2013). The use of self-authorship was not intended to undermine studies of creative work as an individual exercise of biographical work or biographical invention (Adams, 2003; Taylor and Littleton, 2006), the individualistic nature of creative work (Banks and Hesmondhalgh, 2009) or gendered dynamics of the sector (Shade and Jacobson, 2015). Indeed, the researchers recognized that both career decision-making and identity work changes throughout the career lifespan to reflect motivation, meaning making and values.

Identity within complex and emotionally bound work may, however, act as a "cognitive compass" (Fugate et al., 2004: 17) that directs, regulates and sustains work, learning and career decision making (von Rimscha and Siegert, 2011). It is therefore unlikely that the process of self- 
authorship is experienced in the way it is often presented: as a linear process that results in the (permanent) achievement of self-authorship (see Table 1). Thus, the study sought to investigate whether phases of development within the self-authorship framework might reveal the experience of career decision-making in a new way. In particular, the researchers hypothesized that the linearity of self-authorship might be in conflict with the experiences of creative workers and that bringing this to light might contribute to understanding the fluid identities and identity work required across the career lifespan.

Insert Table 1 here

\section{Theoretical framework and research questions}

\section{Self-authorship and career decision-making}

Writing from a constructive-developmental perspective, Kegan (1994) first defined the notion of self-authorship as different orders of mind through which individuals learn to understand and differentiate between external and self-defined expectations. Later defined by Baxter Magolda (1999: 143) as “the ability to collect, interpret, and analyze information and reflect on one's own beliefs in order to form judgments", self-authorship is central to adult decision-making, including that which relates to careers. Self-authorship provides a way of understanding the process that people use to make meaning of their experiences and the advice they receive from others. This incorporates susceptibility to negative feedback and the extent to which the reasoning employed to make a decision reflects an internally grounded sense of self.

Working with university students, Baxter Magolda (2001; 2008; 2009) advanced Kegan's (1994) theory of self-authorship with the addition of epistemological, intrapersonal and 
interpersonal dimensions that conceptualize how people interpret and analyze their experiences (see Table 1). Only when all three dimensions are considered can self-authorship be achieved.

Noting that little empirical research had linked self-authorship and career decision-making, Creamer and Laughlin (2005) extended self-authorship still further, employing it to understand how female university students made meaning of academic and career advice relating to careers in science, technology, engineering and mathematics (STEM) disciplines. Finding that self-authorship impacted decision making in relation to career choice, Creamer and Laughlin's study laid the foundations for research that probes career-self-authorship within career.

Noted earlier, the study reported here sought to investigate whether phases of self-authorship might reveal the experience of career decision-making in a new way and whether the linearity of self-authorship might be at odds with the experiences of creative workers. Such tensions are likely to be experienced even at the pre-career phase when, for example, aspiring creative workers might experience tensions between their creative aspirations and the disapproval of authority figures. The study formed part of a multi-year research project investigating the characteristics of careers among creative industries workers. The research question addressed here is as follows:

Research question: Might the phases of self-authorship framework contribute to contemporary understandings of career decision-making among creative workers?

Illustrated at Table 1, the journey towards self-authorship is traditionally conceptualized as a linear process initially characterized by a reliance on external formulas. At this initial stage, insufficient awareness of personal values and identity implies the need for external approval, leading to an externally defined identity that is easily influenced - hence the likelihood for tension. The crossroads aspects of self-authorship theory can be thought of as provocative moments: growing recognition that knowledge is uncertain and that one's own values and input are important. 
Baxter Magolda (2001) describes this recognition as a place of discontent or tension, where individuals feel the need to work toward internal sources of belief and self-definition rather than accept the authority of others.

At the self-authorship phase, individuals use their internal foundation to evaluate knowledge claims. They also secure internal commitments and trust their internal voices (Baxter Magolda, 2009); they create an identity that is distinct from others' perceptions. The assumption is made that once self-authorship is achieved, it is a permanent state and the basis on which new decisions are made. The idea of permanency was at odds with our previous creative industries research (see, for example, Bennett et al., 2014) and yet many of the creative workers' career narratives produced during the multi-year project reflected phases of self-authorship. Extending Creamer and Laughlin's (2005) work, we hoped that using the framework to analyze the career narratives of creative workers at different stages of their careers might contribute to contemporary understandings of creative workers' decision making.

\section{Method}

Study context

The study was conducted in Australia and the Netherlands. The Netherlands creative industries are considered to be an important driver of innovation and economic growth (Federation of Dutch Creative Industries, 2013) and experienced double the growth of other industries during 2010-2013 (Statistics Netherlands, 2014); this pattern is mirrored in other European countries (Mietzner et al., 2010). Similarly, in Australia the creative industries are "one of the fastest-growing, most dynamic segments of the national economy" (CCI, 2013, n. p), employing some 531,000 workers.

The Netherlands creative industries are characterized by creative business services including landscape architecture, creative games, new media and urban development (Milicevic et al., 2013). 
In Western Australia, creative services such as marketing, software, design and architecture account for $70 \%$ of all creative work and the remaining $30 \%$ of creative work is located in creative production including performing and visual arts, film and television, and publishing (Higgs, 2013). In both sites the number of creative workers is under-reported because part-time and freelance workers are often not included in employment statistics (Mietzner and Kamprath, 2013; Throsby, 2008). Nonetheless, the samples from each site were fairly representative of the known populations.

\section{Recruitment and sample}

Once ethical approvals were obtained from the respective universities, creative industries workers in Australia (Perth) and the Netherlands were recruited using respondent-driven sampling. In Perth these included industry networks, professional associations and industry media. To reduce bias, sampling involved multiple initial sources that aligned with Perth's creative industry sectors. As the creative industries population in Australia is unknown, a response rate cannot be reported. In the Netherlands, the researcher was granted access to the largest creative industries trade union with a total of 4,800 members; participants were recruited through that union's email lists. A total of 511 responses were obtained giving a response rate of $11 \%$, which is common for nonincentivized e-mail surveys (Sheehan, 2001).

Respondents worked in a range of creative disciplines, most often reporting multiple applications of their creative skills (for example, creative writers working as language teachers or journalists). Respondents' primary creative disciplines are shown at Table 2 and demographics of the sample are shown at Table 3.

Insert Tables 2 and 3 here 


\section{Instruments and approach}

The survey instrument (Bennett et al., 2014) sought detailed individual cases of creative work and was distributed electronically and in hard copy. The survey included 58 closed and open-ended questions and repeated items for triangulation, validity and reliability. The instrument amassed data about engagement, motivation and identity, the characteristics of work, distribution of time, formal and informal learning, and demographic information. Back-and-forth translation ensured consistency between the English and Dutch versions.

To understand respondents' career transitions and choices, the study followed Ibarra (2003) and Ibarra and Barbulescu (2010) by asking respondents to tell the story of their career journeys. Story telling helps to make sense of complex experiences by enabling the teller to create meaning of ambiguous and perhaps contradictory experiences (Hoyer and Steyaert, 2015). Two-hundred and fifty written stories (career narratives) were received, and from these, 14 respondents expanded on their stories through individual interviews; these were transcribed and analyzed in combination with the survey responses. Three survey questions are central to this article:

1) Thinking back in time, what are the three most formative events in your career?

2) Can you identify an age, 'moment' or period of time when your career aspirations shifted?

3) If you have a story to share we would love to read or hear it, either in writing, in person or by phone. (Question included in the context of career).

Familiarity with each complete survey response ensured that analysis of the story narratives incorporated the broader accounts of each respondent.

Analysis

Citation: Bennett, D., \& Hennekam, S. (2018). Self-authorship and creative workers' decision making. Human Relations, 71(11), 1454-1477. doi: 10.1177/0018726717747369 
In Phase 1 of the analysis, quantitative data were entered into SPSS and hard copy data were transcribed. Following Strauss and Corbin(1990), the researchers first undertook complete readings of each case. Analysis of open responses began with inductive coding to reveal themes for which the researchers may not have looked (Rivas, 2012). Phase 2 involved an iterative process of coding to develop a codebook, which was modified in line with each new case. In Phase 2, the authors applied the theoretical framework of self-authorship and coded the three target questions deductively. Drawing on familiarity with each case from Phase 1 analysis, the initial codebook and deductive analysis were then combined.

\section{Findings}

The data reveal a complex process of self-authorship during which individuals move back-andforth between reliance on external formulas, crossroads moments or moments of tension, and periods of self-authorship. Moreover, the narratives reveal that multiple concurrent selves can simultaneously be at different phases of self-authorship. In presenting the findings, we include verbatim quotes to ensure that the respondent voice is adequately represented. Where appropriate, we also include quantified data (Maxwell, 2010).

We cannot present a longitudinal view of career; rather, we draw on the 250 in-depth 'snapshots' of practice to describe decision-making as it was experienced by respondents. As such, we present the findings in line with the phases of self-authorship and highlight instances where respondents move back and forth in the self-authorship process.

Phase one: Reliance on external formulas (pre-self-authorship) 
Almost all respondents began their career stories by reflecting on their career choice. As expected, around 90\% emphasized the role of external influences (formulas) including parents and career advisors. Emphasizing that their interest in their creative discipline had begun during childhood, respondents described the process of deciding for or against a creative major at university. In tension with their creative career aspirations, half the respondents recalled being discouraged from pursuing a creative career due to the precarious nature of arts careers and the preference for what three career advisors or parents had described as a "decent" degree. Respondents' reactions to this advice differed. At this formative stage, "validation" of their career choice by others (external formulas) rarely involved Baxter Magolda's (2001) epistemological, intrapersonal or interpersonal dimensions, suggesting that the respondents were not yet selfauthoring. This can be seen in the following quote.

The whole world seemed to try to persuade me that I should do something else instead and that I should keep it as a "nice hobby". (Illustrator, painter, female, 38 years)

Fifteen per cent of respondents reacted to the disapproval of others by reinforcing their wish to pursue a creative career. Going against the expectations of parents and teachers was viewed by authority figures as an act of rebellion; it is also an act of self-authorship in the early stages of career decision-making. In the quote below, the respondent refers to epistemological, interpersonal and intrapersonal dimensions of self-authorship as the basis for his decision. In a linear schema, this would indicate the achievement of self-authorship.

Arts were being perceived as the worst career one could take: uncertain, not well paid and with a low social status. I had everything to go to university and this was clearly expected from me, but instead I chose arts. I chose arts because I didn't want to reproduce the model of my parents, 
because I wanted to be different and do it my way. I broke the pattern, travelled a lot and did everything that was always forbidden. (Art student, sculptor, painter, male 23 years)

The discouraging advice about pursuing a career in the creative industries was in stark contrast to the earlier encouragement of the same external influences, particularly parents and teachers, who were credited by $25 \%$ of respondents with helping them self-define, since childhood, as aspiring creators and performers. Seen in the following quote, other respondents emphasized the importance of positive external validation when they were young adults.

I was being encouraged to continue writing by the tutor of my first creative writing unit at university. When I was awarded a PhD scholarship at age 24, writing went from being a hobby to being my full-time occupation; this allowed me to take my writing more seriously. (English language teacher, writer, female, 35 years)

From a self-authorship perspective, many respondents described tension between their authentic self and a lived, inauthentic self: the denial of self-authorship despite having the internal foundation on which it might be achieved. This was the case for the respondent quoted below, who accepted the advice of her partner despite emphasizing her identity as a writer, producer and actor throughout the survey.

My partner put it simply. He told me I wouldn't be able to make a living from a career in the arts and convinced me I should go and do something else, which I willingly accepted. (Writer, producer, actor, female, 41 years) 
Trust in authority figures was expressed by one-third of the respondents, who described a variety of people who were in a position to "know what was best". In seeking to understand these comments, we turned to Creamer and Laughlin's (2005) distinction between trust in authority figures and the need for approval. Our respondents expressed both. The epistemological dimension emerged only in accounts of career decision-making made after the completion or abandonment of formal studies. In these accounts, although trust in influential others was acknowledged, it was simultaneously recognized as a tension in that it was in conflict with individuals' needs, values and interests: their intrapersonal understanding.

In this study, approval seeking was far less prevalent than trust and was mentioned by only five per cent of respondents. Approval was most often sought at crossroads moments: moments at which respondents sought to relieve relational tensions between competing perspectives, expectations and possibilities (Pizzolato, 2005); these are the focus of the following section. In line with non-linear careers, crossroads moments came at various points in respondents' careers and at different ages. In the following example, tension in mid-career was resolved by the approval of a new spouse.

Finding my current wife (also an artist) who was willing to recognize that my efforts and focus on my art practice was valid and meaningful. (Artist, urban designer, male, 51 years)

Few gendered differences were seen at the pre-authorship phase; however, women appeared more likely to be discouraged from pursuing a creative career. In part this was predicated on the masculine skills or behaviors believed necessary for success in the creative industries. These concerns have foundation: as Mallia (2009) has demonstrated, success in the creative industries can be defined and driven by a male career model that lionizes masculine characteristics. There is also support that selfefficacy, the needs of others (Betz, 1994) and attachment to parents (O'Brien et al., 2000) have more predictive power on career decision-making for women than on men. 
Phase two of self-authorship: Crossroads experiences

As seen above, the process of self-authorship begins with crossroads experiences in which people seek to relieve relational tensions: “one's internal voice begins to unseat external formulas, to internally define one's beliefs, identity, and social relations" (Hodge et al., 2009: 4). Respondents reported that tensions between the authentic self and the lived self often began or resumed each time they experienced a crossroads experience. A range of crossroad experiences was identified, the most common of which concerned relationship changes, geographically disbursed work, under- or unemployment, burnout or ill health. These tensions functioned variously as push- and pull-factors.

In line with Seibert et al. (2016), substantial life events often prompted respondents to think about what they wanted from life: both intra- and inter-personal decision making. For five per cent of respondents, as in the account below, substantial life events catalyzed an intense period of selfauthorship in which the authentic self was privileged.

Five years ago, after my separation, I decided to do the things I most loved. Painting was one of those and also was a help in my healing process. (Artist, arts event manager, Feng shui consultant, female, 46 years)

External and internal catalysts In line with Pizzolato (2005), we distinguished between external and internal catalysts which at crossroad moments prompt workers to re-evaluate tensions between their needs and the needs of others. We emphasize that although external situational factors such as financial security and recognition functioned as catalysts for change, the need for change often came from within. The dominant external catalyst was financial insecurity and was mentioned by $50 \%$ of respondents. Periods of unemployment or under-employment alongside 
access to professional development and equipment led many workers to subsidize their creative work with additional work as required (see also Comunian et al., 2011).

The professional development needs of these workers are often ignored in accounts of portfolio careerists, who form a largely self-managed and "agile freelance pool who must ensure their skill currency [to overcome] a mismatch of applicants' skills to the needs of the job at hand" (Haukka, 2010: 42). Consistent with Throsby and Zednik (2011), workers accepted the necessity of non-arts work and associated skills development only after multiple attempts to establish a creative practice. In some cases, this realization led workers to suspend their creative careers indefinitely. The abandonment or suspension of creative work created new tensions between identity and career, with the creative identity often retained even in the absence of a creative practice.

Some respondents resolved tensions between identity and career by accepting financial insecurity as an inevitable aspect of their careers. These workers negotiated their way through regular crossroads experiences, often with temporary solutions that enabled them to sustain their artistic identity; others found more permanent identity solutions by positioning their unrelated work as a valued aspect of their self as worker. Only three per cent of respondents reported that financial stability had enabled a renewed emphasis on creative practice. This included the narrative from a writer, below.

An arts career was too financially unviable for me to pursue so I undertook psychology and now that I can earn a living from that, $[\mathrm{I}]$ have turned back to the arts. The two now exist side by side. (Clinical psychologist, writer, female, 37 years)

Reported by almost $50 \%$ of respondents, recognition functioned as an external situational pull factor through which creative workers gained career self-efficacy. Recognition was reported in range of 
guises: for example, through sales, royalties, competition wins, demand for work, positive reviews, and successful exhibitions, publications, recordings and performances.

Having my first successful exhibition at a gallery in Sydney. I had had a few shows before but none were as successful as this. It gave me confidence that I could earn a living as an artist. (Artist, leadership development consultant, male, 33 years)

In contrast with career development within a linear career trajectory, however, positive external catalysts such as recognition and demand for work were often impermanent and reputation was insufficient leverage to ensure regular income over time. As such, reputational capital emerged as transitory alliances (Duysters and de Man, 2013) measured not by the duration of the relationship, but by the accomplishment of specific tasks. Tension between self-authorship, approval and authenticity persisted across the career lifespan, highlighting the need for regular engagement with the self-authorship process.

The importance of networking was noted by $66 \%$ of women respondents, who also conveyed that the professional networks in which they could access crucial senior peers and social support were male dominated and difficult to enter (see also Eikhof and Warhurst, 2013; Gill, 2002). These networks are central to success in the creative industries because hiring is "driven by reputation and skills" (McLeod et al., 2011: 123) and underpinned by networked forms of recruitment (Blair, 2001; Manning and Sydow, 2007). It is not surprising, then, that these women felt they traveled on a different and inferior trajectory than men with similar positions and experience. Such reports were common across the static and performative (embodied) arts, as described below.

I thought I would enjoy it more and find places to exhibit much easier. Did not expect the business side of art to be so wanky in that it's again "who you know and how you market" that 
gets you in the door, not the quality of your work necessarily. (Visual artist and writer, female, 39 years)

[I recall] the struggles I had as a young professional woman in my 20s with an excellent education, to obtain professional credibility, experience and status in a profession still largely hostile to women, and especially women who had children. (Musician, female, 52 years)

Eikhof and Warhurst (2013) and Gill (2002) agree that in some creative industries, insufficient transparency combined with closed networks fosters discrimination against women. Indeed, men appear to have greater opportunities to access the field and to develop networks in a group of similar (male) others. As observed by Smith and McKinley (2009), the ease of socialization between and among men is a likely contributor to this as men tend to build relationships that span friendship, social and business ties with other men (see also Broadbridge and Hearn, 2008).

Discrimination and stereotyping was reported by $10 \%$ of female respondents, as seen below.

Discrimination, I have experienced it twice: once as a 28-year old applicant where I was unofficially hired and then it was all cancelled at the last minute because they found out I had a serious relationship and was getting married. A second time was when I got pregnant with my second child and was made redundant ... the organization thought I wouldn't be as flexible and available any more with two kids. (Graphic and digital designer, female, 45 years)

External factors such as these discouraged women from pursuing their creative careers because they did not consider their efforts to be commensurate with the rewards, and the rewards were not perceived to be equitable with those of male colleagues. Discriminatory behaviors included gendered hiring practices, which hindered career progression or pushed women out of the creative 
industries altogether. In other accounts, the expertise of women was denied (see also Banks and Milestone, 2011) and sexism was reinforced by the depiction or placement of women in stereotypical roles (see Jones and Pringle, 2015).

The study revealed women who refused to abandon their creative careers when they encountered discrimination. One woman wrote of establishing private contracting arrangements to bypass the networks from which she had been excluded. As seen below, discrimination and closed networks required women to exercise increased agency and resilience, using their internal foundation to author a solution.

I quit my job as a DJ due to gender discrimination in the workplace. The new manager apparently thought girls weren't as capable and didn't deserve as much pay or hours as the guys, and I wasn't given enough new work by my employer to be able to stay at my job. Since then, I've only been able find DJing work through private contacts. (Multimedia design student, singer/songwriter, DJ, musician, female, 25 years).

In line with Windels and Mallia (2015), women's identity and self-worth was rarely derived solely from their creative work. Rather, women emphasized both personal and professional identities and they wrote of professional identities within and outside the creative industries. Fifteen per cent of female respondents relayed that other aspects of life were equally or more rewarding than their creative work.

Getting a regular job allows for stability and pursuit of other goals and happiness in other things that I can do with my life. Acting is more of an enthusiastic hobby. (Administrator, actor/writer, female, 36 years) 
In these cases, self-authorship encompassed a broad internal foundation that was articulated far more often by women than by men.

To summarize, the data revealed a range of crossroads experiences that prompted a focus on the internally defined beliefs, goals, values and self-conceptions that combine to form selfauthorship. In some cases, however, the identity work associated with crossroads experiences also brought into focus the risks of pursuing a creative career. This led some individuals not to pursue self-authorship. Instead, the data revealed a denial or postponement of authentic self-authorship in order to reconstruct the self in line with the needs and expectations of others.

Gendered catalysts While men and women reported crossroads experiences more or less equally, some catalysts were gender specific. One of these tensions related to work-life balance, which was reported as a challenge by two-thirds of female respondents and only one-quarter of males. Work in the creative industries often features unsociable working hours and irregular incomes, which can be incompatible with family commitments (Banks and Milestone, 2011). In this study, only women stated that they had deferred their plans for a family in order to sustain their careers. It is possible that attrition of female creative workers is unequally influenced by insufficient financial stability and the need to meet carer responsibilities, as described in the following quote.

My biological clock suddenly "going off" was a bit of a shock. It meant that my ability to focus on my creative work was suddenly tempered by my need to spend time parenting, and my need for financial stability increased. (Writer and lecturer, female, 44 years)

Contingent work places the burden of sick leave and parental leave on the individual worker (Gill, 2002) and can lead to the attrition or partial withdrawal of workers when they start a family (see Banks and Milestone, 2011). In the creative industries, as in other sectors such as consulting or in 
politics where presenteeism is required (see Chatman and Jehn, 1994; Eikhof and Warhurst, 2013), these factors are exacerbated by tight deadlines, long and unsocial working hours, and geographically dispersed work that demands frequent travel (Gill, 2002).

Women are more likely than are men to need to reconcile these factors with carer commitments (Mallia, 2009). In this study, respondents whose practice was static or non-performative (for example, visual artists and designers) were better able to leverage the flexibility of contingent work to balance work and family. For these workers, around $15 \%$ of the sample, career change was less commonly linked to attrition.

After completing a Diploma of Art and Design in Graphic Design, I worked in the printing and graphic design industry until I had my first child. I then began working freelance from home. ... Working from home gave me the freedom to take up painting again. (Graphic designer, painter, female, 36 years)

We note, however, that women are more likely than men to experience career latency and that the loss of technical proficiency during periods of career latency can be devastating to workers in industries such as music and dance, where creative work is embodied (Bennett and Bridgstock, 2015).

\section{Phase three: Self-authorship}

Self-authorship emphasizes that mature internal decision-making relies on complex ways of seeing oneself and one's relations with others (Baxter Magolda, 2004). This involves epistemological, intrapersonal and interpersonal maturity, all of which are evident in the following quote. 
My parents know me well, so I basically followed their advice during high school. However, while they probably know what is best for me in terms of earning a good income, they do not know what is going on inside me. They have not understood that I don't care about money, but that doing something meaningful and giving back to society and nature is more important. (Theater maker, female, 30 years)

As seen above, self-authorship involves an internally grounded sense of self that guides the interpretation of experience and choices, the ability to evaluate and interpret knowledge claims in light of the available evidence, and the capacity to genuinely consider others' perspectives without being overshadowed by them (Baxter Magolda, 2004). The process of self-authorship has most often been studied with university students, with the aim of cultivating a secure sense of self and epistemological maturity prior to graduation (see Baxter Magolda, 1999; 2001; 2004; Creamer and Laughlin, 2005). Some of the respondents in this study self-authored at that age, as seen below.

I was told in high school that I would never make any money as an artist and I should be a journalist instead. I did try and I bloody hated journalism. At age 25 I realized I had half an arts degree in a subject I was bored with, and no money anyway. ... I finally listened to myself and became a photographer. (Photographer, female, 26 years)

However, in line with Cabrera (2007) the desire for authenticity was more often discussed by older respondents.

It took me years to realize who I am and what I want in life. Art is an important part of my identity, and although in the past I let others' judgement guide my behaviour I have finally 
understood that while others' ideas are important to me, I also have to listen to my internal voice. (Sculptor, female, 58 years)

Drawing on survey responses and stories, the study reported here asked whether the phases of selfauthorship might contribute to contemporary understandings of creative workers' career decisionmaking. In reality, respondents' narratives contributed to contemporary understandings of selfauthorship. The fluidity of self-authorship forms the basis of the discussion.

\section{Discussion}

Theoretical contributions: Self-authorship in practice

Emphasized in the self-authorship framework, self-identity-how one sees oneself (Ashforth et al., 2008) — is a socially constructed, developmental process. Ibarra and Barbulescu (2010) and Maitlis (2009) warn that the need to feel accepted, to have one's identity validated by others, can lead to tensions between one's own sense of self and the opinions of others. This can be particularly challenging for workers who identify strongly with their work (Duffy and Dik, 2013) and may influence the identity work undertaken at crossroads moments, particularly when career calling motivates workers to persevere through failure (Duffy and Dik, 2013).

The (identity) tensions between one's authentic self and the norms and expectations of family and society have been identified previously and may be especially prevalent in the careers of people in precarious professions. This is borne out by social identity theory, which emphasizes the need for individuals to construct a self that is validated by others; in the case of creative workers, the process of validation may be repeated regularly as individual workers move in and out of roles deemed by influential others to be more or less successful.

Following Creamer and Laughlin (2005), the three phases of self-authorship were considered alongside interpersonal, epistemological and intrapersonal dimensions of self and decision making. 
Many respondents described fluid identity work consisting of multiple selves, each of which might be self-authored to a different degree and prioritized according to need and opportunity. Although few respondents described synchronous or stable self-authorship behaviors, some created stability by aligning their core identity with their art form.

My authentic self is somehow related to music, that's clear. However, in what form that will be is constantly changing. I first saw myself as a performer or rather an aspiring performer, but with time I noticed that other related aspects such as writing, mentoring younger musicians or teaching were enjoyable too. I would say I have multiple "me's" with the overruling theme being music. (Flutist, composer, teacher, female, 55 years)

The first theoretical contribution relates to the impermanence of self-authorship. In this study, selfauthorship was typically disrupted by crossroad moments which led individuals to resolve relational conflict by moving back to the crossroads or even pre-authorship phase of self-authorship in order to continue their identity work. In the following quote, the respondent presents key decision points in chronological order.

There are various key moments: choosing art ahead of money at 20. Deciding at 20 years of age, after three years' full time work in a medical laboratory, that I did not value money, but creativity. That I could not live my life "earning a living", but had to live my life creatively above all other considerations. And quitting my full-time job, getting a part time one, and beginning to design and make clothes, write songs... Then in the past five years having to aspire instead to keep a roof over my head and pay the rent as it became less feasible to live on low income. (writer, journalist, editor, arts producer, female, 49 years) 
At Figure 1, non-linearity is illustrated using excerpts from a painter's narrative, which are organized according to the phases of self-authorship.

Insert Figure 1 here

The fluidity expressed above is at odds with Kegan's (1994) estimation that no more than half of US adults reach self-authorship, which is defined as a stable end point. Rather, self-authorship emerged as a complex, non-linear and consistent feature of career decision-making across the career lifespan. Workers who encounter multiple concurrent roles, career transitions and career crossroads engage in self-authorship in a fluid and complex way, often authoring several selves in order to resolve tension and make sense of the whole. This includes behaviors that can appear internally founded even before self-authorship is sufficiently developed for that to occur. Conversely, individuals who encounter crossroads moments throughout the career lifespan may return to the authority of others even when self-authorship had been previously achieved.

External formulas are important, and our study reveals the tension created by a significant shift in the thinking of authority figures, experienced most often at the point of choosing a career path or negotiating a crossroads moment. The development of talent relies on the support and encouragement of influential others, predominantly parents and teachers (McPherson, 2009). Authority figures are also pivotal influences in the development of self-esteem and authentic identity (Costas and Fleming, 2009), which respondents in this study described as their artistic identity. Thus, the artistic identity is often encouraged and supported from childhood, and yet when it comes to vocational decision-making, authority figures-particularly parents — can reject the 
creative industries in favor of career paths with more secure or socially respected outcomes. This "change of mind" positions the authentic self as one that is now deemed inappropriate.

Changes in career thinking and behavior inevitably impact self-identity (Alvesson, 1998), and in these circumstances people are thought to engage in self-affirming identity work during which they seek to resolve tension by questioning and disengaging from one identity while exploring and eventually integrating another (see Conroy and O'leary-Kelly, 2014). Beech (2011:290) argues that identity transition might be far less linear than this, featuring temporary or liminal identities constituted "by a weaving together of practices". This was evident in research undertaken by Hennekam and Bennett (2016) and Hennekam (2017), who found that attritioned artists retained their artist identities over a long period of time as one of multiple selves privileged according to context.

Beech (2011) also suggests that the perpetuation of identity work can be deliberate, and evidence of this was found in the account of a painter, quoted below.

I'm not sure yet what I want with my life, where my ambition lies. It must sound strange, but this on-going uncertainty suits me, it seems part of me. Working on lots of projects, having different roles, both within and outside the creative realm, it's all part of who I am and the career I want, I'm not looking for fame or to become an established artist - this multitude of aspects is who I am. (Painter, poet, writer, female, 51 years)

Following on from Beech's earlier work (2011), Beech, Gilmore, Hibbert and Ybema (2016: 507) studied identity work among Indie rock musicians and confirmed that musicians do not necessarily engage in self-affirming identity work to resolve identity tension. Rather, they can perpetuate selfquestioning identity work in order to sustain the conflict: "for their sense of who they are, the struggle is essential, not the outcome". The painter quoted above had achieved self-authorship in 
that she had employed the dimensions of self-authorship in self-questioning identity work to make sense of multiple selves; however, in line with Beech et. al., she perpetuated uncertainty and conflict because they were core to her identity.

The data confirm Pizzolato's (2005) distinction between internal and external catalysts, and the second theoretical contribution is to highlight catalysts that are gendered. Across the career lifespan, women experience more fluctuation in their work and career orientations than men (see also Walters, 2005). The findings suggest that despite gendered challenges for women in the creative industries, women are more likely than men to achieve self-authorship. Women related this to the positive impact of endorsements (Harrison and Jepsen, 2015) and their emergence from negative experiences with high levels of resilience and agency.

There is evidence for this in previous research with students who had experienced marginalization (see Abes and Jones, 2004; Pizzolato, 2003; Torres, 2010) and who found themselves more likely than their peers to demonstrate self-authoring approaches. Previous studies also suggest that individuals who have experienced discrimination and diversity can be more open to multiple perspectives (see Torres 2003; Torres and Baxter Magolda, 2004) and to opportunities to author their authentic identities and beliefs (Abes and Jones, 2004).

Moments that are painful and confusing can also present "the opportunity for people to reorganize their experiences and engage with a stronger personal identity" (Hoyer and Steyaert, 2015: 1858). This is in line with our finding that the tensions addressed in crossroad moments allow individuals to reflect on what they want in life, sometimes becoming aware of suppressed or unconscious desires. While Hoyer and Steyaert (2015) opt for a psychanalytic framework, we suggest that the self-authorship lens might frame meaningful reflection at crossroads moments, thus making visible previously hidden or conflictual feelings and unconscious wishes and fears. It follows that negative experiences will prompt some individuals to recognize and acknowledge the 
tension between external influences and their internal voices and identities, stimulating the independent thoughts and actions needed to reconcile them.

The study suggests that the impact of marginalization on self-authorship is not limited to university students. In this instance, some women, as a minority group in the male-dominated creative industries, confronted difficult decisions or disadvantage by becoming increasingly agentic in their career decision-making. Self-authorship approaches underpinned increased agency, resilience and determination. However, this finding needs to be read with caution; the study sampled active creative industries workers and did not hear stories from women whose negative experiences, including discrimination, had driven them from the creative industries altogether. Moreover, the women able to overcome marginalization with these strategies were often more mature in their selfauthorship and more experienced in their careers. We note that some women sought to overcome marginalization by adopting stereotypically masculine behayiors, which might in fact enhance the risk of harassment (see Leskinen et al., 2015) as well as perpetuating masculine norms.

The third and related contribution is the identification of covert self-authorship. Individuals with a strong internal foundation (self-authorship) may choose not to act on their career calling because of factors such as a desire for financial security; other people, at the pre-authorship or crossroads phase, are dissuaded from following their calling. Career calling was often acted upon over time, but it was sometimes made visible to other people only after a period of complex identity work during which the tension was hidden. We define this as covert self-authorship, and the narratives suggest that it can be present even within student populations.

Covert self-authorship and non-linear career paths compound the complexity of career decision-making to the extent that some individuals self-author multiple simultaneous selves as, for example, artist, administrator, teacher, and non-arts worker; these selves are unlikely to be equally self-authored or equally valued. That the respondents emphasized relationships of trust far more 
commonly than they emphasized the approval of authority figures suggests that the selection of approvers for these selves may be far more complex than is often assumed.

\section{Practical implications}

The study has implications for educators, workers and organizations. Although this article does not have an educational focus, we emphasize that across higher education, awareness of creative industries practice is often overlooked in favor of developing technical expertise. Students would benefit from industry experience, career development and open discussions about the breadth of practices inherent within creative industries work. Indeed, Pizzolato (2005: 624) advocates the need for students to experience externally induced tensions - she calls these provocative momentswhich result in disequilibrium and prompt students to "integrate their identity with their cognitive skills".

Exploration of narrowly constructed or diffuse artistic identities is also likely to lessen the risk of personal and professional identity uncertainty as students transition into the workplace (Nyström, 2009). Moreover, supported identity work, perhaps in the form of provocative moments embedded within study, has the potential to foster the acceptance of a whole practice - the necessary and ideal, personal and collective, creative and functional — as valued components of the artist self.

Returning to gender, we acknowledge that both men and women experience many of the career challenges outlined in this article; however, gender merits further discussion. Leslie and Catungal (2012) contend that many women are unprepared to negotiate the masculine culture of the creative industries. We note that the demographic of staff and students in educational institutions tends to be far more gender neutral than in the creative industries (Windels et al., 2010) and that educators have an important role to play in increasing gender sensitivity among students (Spurk et al., 2015). The authors also propose that more women would overcome discriminatory behavior if they were made aware of it and if they graduated with established networks and counter-strategies. 
Increased awareness of gendered disadvantage is insufficient without preventative action from established workers and organizations. In this respect, the creative industries could learn from the gendered action and scholarship already established within STEM disciplines such as engineering. These include the creation of female role models alongside non-discriminatory performance appraisals, hiring processes, workplace supports and promotions practices (see Fouad et al., 2016; Mallia, 2009; McLeod et al., 2009).

\section{Limitations and future research directions}

Every study has limitations and these are outlined here. First, the authors acknowledge that creative industries sectors are not homogeneous in terms of scale, practices and demographics (Dodd, 2012). By design, this study looked at career journeys and made distinctions only when they arose from the data; future research might focus on a single sector to create a nuanced understanding. Next, participants reported on their stories in a retrospective manner. Memories are subject to decay and re-elaboration, and longitudinal studies of creative industries work would be beneficial. Future research might also target attritioned creative workers, who were beyond the scope of this study.

There is potential for similar studies focused on gender. Few studies, for example, have examined why there is gender inequity in the creative industries (see Windels and Mallia, 2015). Neither have studies resolved whether the under-representation of women is due to career attrition or to disproportionate entry level hiring (see Mallia, 2009). In the creative industries, career decision-making is influenced by organizational cultures and by normative and structural constraints in gender, family relations and labor market relations (see McRae, 2003). In this study, these constraints included work-life balance, discrimination, role stereotypes, gendered networks, insufficient female role models and organizational politics (de Vries et al., 2006). Reports of such constraints across the career lifespan suggest the need for longitudinal research that explicitly seeks 
to understand the impact of gender on career decision-making from the point of initial career choice and including workers who attrition.

The pre-authorship phase, in which external formulas in the form of influential others are central to career decision making, is an important phase for future research on the tensions between identity and career. The findings also highlight the impact of a change or reversal in authority view, particularly when parents and others offer conflicting authority views. This merits further research attention and brings into question the motivation and purpose of post-secondary study.

The data illustrate the role of self-authorship in career decision-making, but they also indicate that the linear view of self-authorship is insufficient, even with university cohorts. Future research might investigate the authorship of career decision making in line with ego identity development and career self-efficacy. The expectations of family, friends, teachers and society were reported differently by both sexes and also warrant further research. Researchers might seek to understand multiple self-authorships in cases where intrinsic and extrinsic career identities differ. In particular, the challenges of entering and sustaining a creative industries career might see workers self-author multiple, simultaneous selves: for example, in one career role and not another, and in one identity and not another, until such time as authenticity is sought or self-questioning work is perpetuated.

\section{Acknowledgements}

We would like to thank Tim Kuhn, Editor-in-Chief, as well as the anonymous reviewers of Human Relations, for their constructive and insightful comments on an early version of this article.

\section{Funding}

This research received no specific grant from any funding agency in the public, commercial, or notfor-profit sectors. 


\section{References}

Abes ES and Jones SR (2004) Meaning-making capacity and the dynamics of lesbian college students' multiple dimensions of identity. Journal of College Student Development 45(6): $612-632$.

Acker J (2007) Inequality regimes: Gender, class, and race in organizations. In JZ Spade, CG Valentine (eds) The kaleidoscope of gender; Prisms, patterns, and possibilities. Thousand Oaks, CA: Sage, 435-355.

Adams M (2003) The reflexive self and culture: A critique. British Journal of Sociology 54(2): 221-38

Alvesson M (1998) Gender relations and identity at work: a case of masculinities and femininities in an advertising agency. Human Relations 51(8): 969-1005.

Ashforth BE, Harrison SH and Corley KG (2008) Identification in organizations: An examination of four fundamental questions. Journal of management 34(3): 325-374.

Banks M and Hesmondhalgh D (2009) Looking for work in creative industries policy. International Journal of Cultural Policy 15(4): 415-430.

Banks M and Milestone K (2011) Individualization, gender and cultural work. Gender, Work \& Organization 18(1): 73-89.

Baxter Magolda MB (ed.) (1999) Creating contexts for learning and self-authorship: Constructive-developmental pedagogy. Nashville, TN: Vanderbilt University Press.

Baxter Magolda MB (ed.) (2001) Making their own way: Narratives for transforming higher education to promote self authorship. Sterling, VA: Stylus.

Baxter Magolda MB (2004) Learning partnerships model: A framework for promoting selfauthorship. In: Baxter Magolda MB, King PM (eds) Learning partnerships: Theory and models of practice to educate for self-authorship, Sterling, VA: Stylus, 37-61. 
Baxter Magolda MB (2008) Three elements of self-authorship. Journal of College Student Development 49(4): 269-284.

Baxter Magolda MB (ed.) (2009) Authoring your life: Developing an internal voice to navigate life's challenges. Sterling, VA: Stylus.

Beech N (2011) Liminality and the practices of identity reconstruction. Human Relations 64(2): 285-302.

Beech N, Gilmore C, Hibbert P and Ybema S (2016) Identity-in-the-work and musicians' struggles: the production of self-questioning identity work. Work, Employment \& Society 30(3): 506-522.

Bennett D and Bridgstock R (2015) The urgent need for career preview: Student expectations and graduate realities in music and dance. International Journal of Music Education, 33(3): 263277.

Bennett D, Coffey J, Fitzgerald S, Petocz P and Rainnie A (2014) Beyond the creative: Understanding the intersection of specialist and embedded work for creatives in metropolitan Perth. In Hearn G, Bridgstock, R, Goldsmith B, Rodgers J (eds) Creative work beyond the creative industries: Innovation, employment, and education, Cheltenham: Edward Elgar Publishing, 158-174Betz NE (1994) Basic issues and concepts in career counseling for women. In Walsh WB, Osipow SH (eds) Career counseling for women, Hillsdale, NJ: Erlbaum, 1-42.

Blair H (2001) You're only as good as your last job: the labour process and labour market in the British film industry. Work, Employment and Society 15(1): 149-169.

Broadbridge A and Hearn J (2008) Gender and Management: New Direction in Research and Continuing Patterns in Practice. British Journal of Management, 19(1): 38-49. 
Burke RJ and McKeen CA (1996) Do women at the top make a difference? Gender proportions and the experiences of managerial and professional women. Human Relations 49(8): 10931104.

Cabrera EF (2007) Opting out and opting in: understanding the complexities of women's career transitions. Career Development International 12(3): 218-237.

Caves RE (ed.) (2000) Creative Industries. Cambridge: Harvard University Press.

CCI: ARC Centre of Excellence for Creative Industries and Innovation. (2013). Creative economy report card. Available at: http://www.cci.edu.au/Creative_Economy_report_card.pdf

Chatman JA and Jehn KA (1994) Assessing the relationship between industry characteristics and organizational culture: how different can you be? Academy of Management Journal 37(3): $522-553$

Coffey JS (2012) Youth career choices: A comparison of industry and ballet. Unpublished doctoral thesis, Curtin University, Western Australia, Australia.

Comunian R, Faggian A and Jewell S (2011) Winning and Losing in the Creative Industries: An Analysis of Creative Graduate's Career Opportunities across Creative Disciplines. Cultural Trends 20(3-4): 291-308.

Conroy SA and O'Leary-Kelly AM (2014) Letting go and moving on: Work-related identity loss and recovery. Academy of Management Review 39(1): 67-87.

Costas J and Fleming P (2009) Beyond dis-identification: A discursive approach to self-alienation in contemporary organizations. Human Relations 62(3): 353-378.

Creamer EG and Laughlin A (2005) Self-authorship and women's career decision making. Journal of College Student Development 46(1): 13-27.

Cunningham S and Higgs P (2010) What's your other job? A census analysis of arts employment in Australia. Melbourne: Australia Council for the Arts. 
Daskalaki M (2010) Building 'bonds' and 'bridges': Linking tie evolution and network identity in the creative industries. Organization Studies 31(12): 1649-1666.

de Vries J, Webb C and Eveline J (2006) Mentoring for gender equality and organizational change. Employee Relations 28(6): 573-587.

Dodd F (2012) Women leaders in the creative industries: a baseline study. International Journal of Gender and Entrepreneurship 4(2): 153-178.

Duffy RD and Dik BJ (2013) Research on calling: What have we learned and where are we going? Journal of Vocational Behavior 83(3): 428-436.

Duysters G and Man AP (2003) Transitory alliances: an instrument for surviving turbulent industries? R\&D Management 33(1): 49-58.

Eikhof DR (2014) Transorganisational work and production in the creative industries. In C Bilton, S Cummings (eds) Handbook of Management and Creativity. Cheltenham: Edward Elgar Publishing, 275-297.

Eikhof DR and Warhurst C (2013) The promised land? Why social inequalities are systemic in the creative industries. Employee Relations 35(5): 495-508.

Evans O and Steptoe A (2002) The contribution of gender-role orientation, work factors and home stressors to psychological well-being and sickness absence in male-and female-dominated occupational groups. Social science \& medicine 54(4): 481-492.

Federation of Dutch Creative Industries (2013) Cross-over works: Innoveren met de creatieve industrie. Amsterdam: Federation of Dutch Creative Industries.

Fouad NA, Singh R, Cappaert K, Chang W-H and Wan M (2016) Comparison of women engineers who persist in or depart from engineering. Journal of Vocational Behavior 92: 79-93.

Fugate M, Kinicki AJ and Ashforth BE (2004) Employability: A psycho-social construct, its dimensions, and applications. Journal of Vocational behavior 65(1): 14-38. 
Gill R (2002) Cool, creative and egalitarian? Exploring gender in project-based new media work in Europe. Information, Communication and Society 5(1): 70-89.

Harrison B and Jepsen DM (2015) The career impact of winning an external work-related award. Journal of Vocational Behavior 89: 21-31.

Haukka S (2010) Education-to-Work Transitions of Aspiring Creatives. Cultural Trends 20(1): 41-64.

Hennekam S and Bennett D (2016). Involuntary career transition and identity within the artist population. Personnel Review, 45(6): 1114-1131.

Hennekam S and Bennett D (2017) Sexual Harassment in the Creative Industries: Tolerance, Culture and the Need for Change. Gender, Work \& Organization, 24(4): 417-434.

Hennekam S (2017) Dealing with multiple incompatible work-related identities: the case of artists. Personnel Review, 46(5): 970-987.

Higgs P (2013) Creative industries statistical analysis for Western Australia. Brisbane: CCI.

Hodge DC, Baxter Magolda MB and Haynes CA (2009) Engaged learning: Enabling selfauthorship and effective practice. Liberal Education, 95(4): 16-23.

Hoyer P and Steyaert C (2015) Narrative identity construction in times of career change: taking note of unconscious desires. Human Relations 68(12): 1837-63.

Ibarra H (2003) Working identity: Unconventional strategies for reinventing your career. Boston: Harvard Business School Press.

Ibarra H and Barbulescu R (2010) Identity as narrative: Prevalence, effectiveness, and consequences of narrative identity work in macro work role transitions. Academy of Management Review 35(1): 135-154.

Jones D and Pringle JK. (2015) Unmanageable inequalities: Sexism in the film industry. The Sociological Review 63(S1): 37-49. 
Kegan R (ed.) (1994) In over our heads: The mental demands of modern life. Cambridge, MA: Harvard University Press.

Leskinen EA, Rabelo VC and Cortina LM (2015) Gender stereotyping and harassment: A catch22 for women in the workplace. Psychology, Public Policy, and Law 21(2): 192-204.

Leslie D and Catungal JP (2012) Social justice and the creative city: class, gender and racial inequalities. Geography Compass 6(3): 111-122.

Luonila M and Johansson T (2016) Reasons for Networking in Institutionalized Music

Productions: Case Studies of an Opera House and a Music Festival. International Journal of Arts Management, 18(3): 50-66.

Maitlis S (2009) Who am I now? Sensemaking and identity in posttraumatic growth. In LM Roberts, JE Dutton (eds) Exploring positive identities and organizations: Building a theoretical and research foundation. New York: Routledge, 47-76.

Mallia KL (2009) Rare birds: Why so few women become ad agency creative directors. Advertising and Society Review 10(3): 1-13.

Manning S and Sydow J (2007) Transforming creative potential in project networks: how TV movies are produced under network-based control. Critical Sociology 33(1/2): 19-42.

McKeen CA and Burke RJ (1994) An exploration study of gender proportions on the experiences of managerial and professional women. International Journal of Organizational Analysis 2(3): $280-294$.

McKinlay A and Smith C (2009) Creative Labour: Working in the Creative Industries. London: Palgrave Macmillan.

McLeod C, O'Donohoe S and Townley B (2009) The elephant in the room? Class and creative careers in British advertising agencies. Human Relations 62(7): 1011-1039. 
McLeod C, O’Donohoe S and Townley B (2011) Pot noodles, placements and peer regard:

creative career trajectories and communities of practice in the British advertising industry. British Journal of Management 22(1): 114-131.

McPherson GE (2009) The role of parents in children's musical development. Psychology of Music 37(1): 91-110.

McRae S (2003) Constraints and choices in mothers' employment careers: a consideration of Hakim's Preference Theory. British Journal of Sociology 54(3): 317-338.

Maxwell JA (2010) Using numbers in qualitative research. Qualitative Inquiry 16(6): 475-482. Milicevic' V, Ilié B and Sofronijevié A (2013) Business aspects of creative industries from a global perspective. Management Journal for Theory and Practice Management 66: 5-13.

Mietzner D and Kamprath M (2013) A competence portfolio for professionals in the creative industries. Creativity and Innovation Management 22(3): 280-294.

Mietzner D, Kamprath M and Wagner D (2010) Zukunftsperspektiven und

Kompetenzentwicklungen in der Medienbranche: Eine Szenarioanalyse, Gesellschaft von Freunden der Hochschule für Film u. Fernsehen 'Konrad Wolf'.

Nyström S (2009) The dynamics of professional identity formation: Graduates' transitions from higher education to working life. Vocations and Learning 2(1): 1-18.

O’Brien KM, Friedman SM, Tipton LC and Linn SG (2000) Attachment, separation, and women's vocational development: A longitudinal analysis. Journal of Counseling Psychology 47(3): 301-315.

Pizzolato JE (2003) Developing self-authorship: Exploring the experiences of high-risk college students. Journal of College Student Development 44(6): 797-812.

Pizzolato JE (2005) Creating crossroads for self-authorship: Investigating the provocative moment. Journal of College Student Development 46(6): 624-641. 
Randle K Leung WF and Kurian J (2007) Creating Difference. Creative Industries Research and Consultancy Unit, University of Hertfordshire.

Rivas C (2012) Coding and analysing qualitative data. In Seale C (ed). Researching society and culture. Thousand Oaks, CA: Sage, 366-392.

Seibert SE, Kraimer ML and Heslin PA (2016) Developing career resilience and adaptability. Organizational Dynamics 3(45): 245-257.

Shade LR and Jacobson J (2015) Hungry for the job: Unpaid internships and the creative industries. The sociological review 63(S1):188-205.

Sheehan KB (2001) E-mail survey response rates: A review. Journal of Computer-Mediated Communication, 6(2): 0.

Skillset (2010) Women in the Creative Media Industries. London: Skillset.

Smith C and McKinlay A (2009) Creative labour: Content, contract and control. In McKinlay A, Smith C (eds) Creative labour: Working in the creative industries. London: Palgrave MacMillan, 29-50.

Spurk D, Kauffeld S, Barthauer L and Heinemann NSR (2015) Fostering networking behavior, career planning and optimism, and subjective career success: An intervention study. Journal of Vocational Behavior 87: 134-144.

Statistics Netherlands (2014) Topsectoren groeien tweemaal zo snel als de hele economie. Heerlen: CBS.

Strauss A and Corbin J (eds.) (1990) Basics of qualitative research. Newbury Park: Sage.

Taylor S and Littleton K (2006) Biographies in talk: a narrative-discursive research approach. Qualitative Sociology Review 2(1): 22-38.

Thanki A and Jeffreys S (2007) Who are the fairest? Ethnic segmentation in London's media production. Work Organisation, Labour and Globalisation 1(1): 108-18. 
Throsby D (2008) Creative Australia: The arts and culture in Australian work and leisure.

Canberra: Academy of the Social Sciences in Australia.

Throsby D and Zednik A (2011) Multiple job-holding and artistic careers: Some empirical evidence. Cultural trends 20(1): 9-24.

Torres V (2003) Factors influencing ethnic identity development of Latino college students in the first two years of college. Journal of College Student Development 44(4): 532-547.

Torres V (2010) Investigating Latino ethnic identity within the self-authorship framework. In Baxter Magolda BM, Creamer EG Meszaros PS (eds) Development and assessment of selfauthorship: Exploring the concept across cultures, Sterling, VA: Stylus, 67-84.

Torres V and Baxter Magolda MB (2004) Reconstructing Latino identity: The influence of cognitive development on the ethnic identity process of Latino students. Journal of College Student Development 45(3): 333-347.

United Nations (2013) UN Conference on Trade and Development Creative economy report 2013 special edition: Widening local development pathways. Available at: http://www.unesco.org/culture/pdf/creative-economy-report-2013.pdf von Rimscha MB and Siegert G (2011) Orientations of entertainment media workers: entertainment media workers-disrespect and neglect. Media, Culture \& Society 33(7): 10091026.

Walters S (2005) Making the best of a bad job? Female part-timers' orientations and attitudes to work. Gender, Work and Organization 12(3): 193-216.

Windels K and Lee W (2012) The construction of gender and creativity in advertising creative departments. Gender in Management: An International Journal 27(8): 502-519.

Windels K, Lee W and Yeh Y (2010) Does the creative boys' club begin in the classroom? Journal of Advertising Education 14(2): 15-24. 
Windels K and Mallia L (2015) How being female impacts learning and career growth in advertising creative departments. Employee Relations 37(1): 122-140.

Wreyford N (2015) Birds of a feather: informal recruitment practices and gendered outcomes for screenwriting work in the UK film industry. The Sociological Review, 63(S1): 84-96.

Yoder JD (2002) Context matters: understanding tokenism processes and their impact on women's work. Psychology of Women Quarterly 26(1): 1-8. 
Table 1: The development of self-authorship, presented as a linear process

\begin{tabular}{l|lll} 
Pre-authorship & The self-authorship process & Self-authorship \\
\hline$\underline{\text { External formulas }}$ & $\underline{\text { Crossroads }} \underline{\text { Self-authorship }}$ & Internal foundation
\end{tabular}

Epistemological dimension: How do I know?

$\begin{array}{ll}\text { Defer to authority } & \text { Realize the need to Defer to own beliefs Act on the basis of } \\ \text { have input } & \text { internal beliefs }\end{array}$

Interpersonal dimension: Who am I in relationship with others?

\begin{tabular}{l|l|l}
$\begin{array}{l}\text { Defer to others } \\
\text { Realize the need for }\end{array}$ & Define values and \\
self-definition & identity & sense of self \\
Intrapersonal dimension: who am I? & Include authenticity & Act on the basis of \\
Seek the approval of & Realize the need for $\quad$ in decision making & self-determined \\
others & authenticity & beliefs
\end{tabular}




\section{Table 2: Respondents' primary creative practices}

Discipline cluster $\quad$ Count

Performative arts (theatre, music, dance and film) 212

Production (producers, editors, theatre technicians and film makers) 64

Visual arts (e.g. painting, illustration, sculpting, photography)

Design (fashion, landscape, graphic design)

Teaching (music, visual arts, writing)

27

Not specified

Writing (creative writing, poetry, script writing)

\section{Table 3: Sample characteristics}

\begin{tabular}{|c|c|c|c|}
\hline & $\underline{\text { Total sample }}$ & The Netherlands & Australia \\
\hline Participants & & 511 & 182 \\
\hline Average age & & 51.9 & 43.6 \\
\hline Gender ratio male: female $(\%)$ & $43: 57$ & $44: 56$ & $41: 59$ \\
\hline
\end{tabular}




\section{Self-authorship}
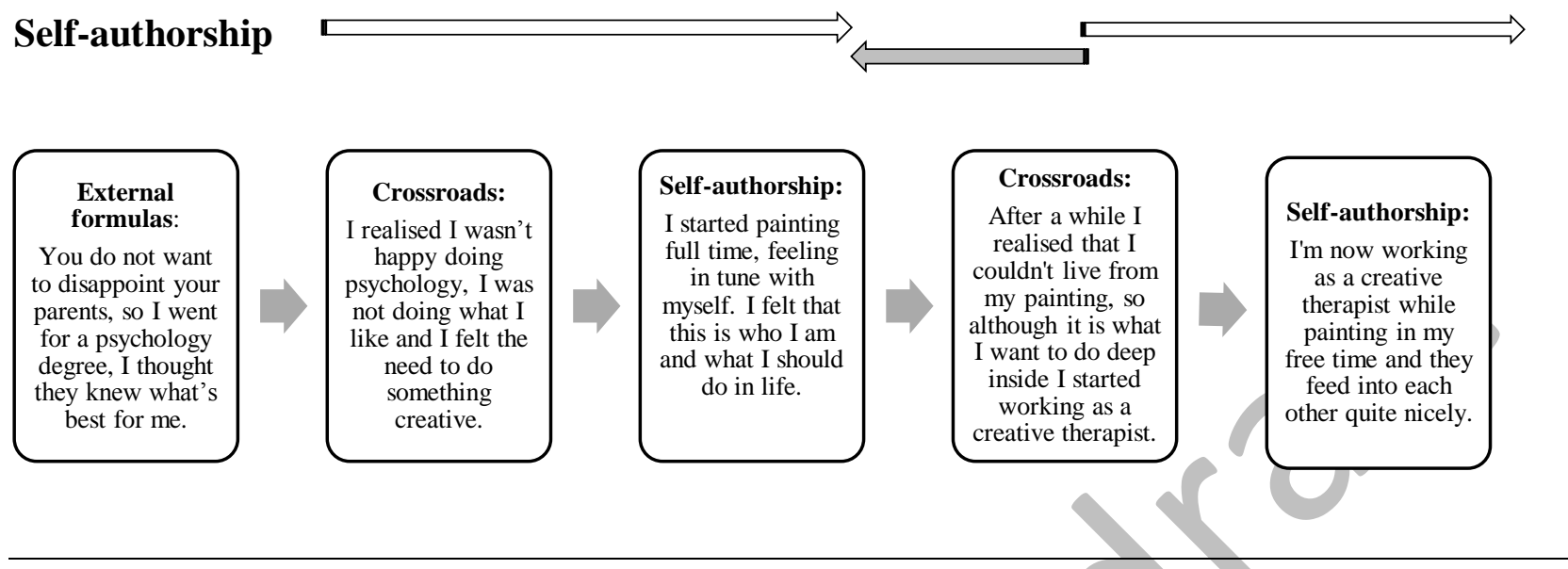

Figure 1: Example of a respondent's process towards self-authorship

Sophie Hennekam is an associate professor at Audencia School of Management in France. She studies identity and identity transitions, diversity management and the creative industries. She has published in a variety of outlets including Journal of Vocational Behavior, Human Resource Management Journal and Gender, Work and Organization. Email: hennekamso@esc-larochelle.fr

Dawn Bennett is Distinguished Professor of Higher Education with Curtin University. Her research focuses on the development of employability, including identity and graduate work. In her work as a National Senior Australian Learning and Teaching Fellow, Dawn is operationalising a metacognitive model for employability with faculty and students in Australia, the UK, Europe and the US. Publications appear at Academia.edu. d.bennett@curtin.edu.au 


\section{Corresponding author:}

Dawn Bennett

Research and Graduate Studies

Curtin University

Perth

Australia

d.bennett@curtin.edu.au

\section{Other Author(s):}

Sophie Hennekam

Human Resources Management Department

Audencia School of Management

8 route de la Jonelière

44312 Nantes

France

$\mathrm{T}:+33613114343$

hennekamso@esc-larochelle.fr 